\title{
Futbolda Penaltı Vuruşunun Kinematiği: Kaleci ve Hedef Faktörünün Etkisi
}

\author{
Kinematic Analysis of Penalty Kick in Soccer: Effect of \\ Goalkeeper and Target Factor
}

\author{
${ }^{1}$ Asım TUNÇEL \\ ${ }^{2}$ Erbil HARBİLI \\ ${ }^{3}$ Serdar ARITAN \\ ${ }^{1}$ Namık Kemal Üniversitesi, Beden \\ Eğitimi ve Spor Yüksekokulu, \\ Tekirdağ, Türkiye \\ ${ }^{2}$ Selçuk Üniversitesi, Spor Bilimleri \\ Fakültesi, Konya, Türkiye \\ ${ }^{3}$ Hacettepe Üniversitesi, Spor \\ Bilimleri Fakültesi, Ankara, Türkiye
}

\section{Yazışma Adresi}

Corresponding Address:

Öğr. Gör. Asım TUNÇEL

ORCID: 0000-0003-1182-4497

Tekirdağ Namık Kemal Üniversitesi Beden Eğitimi ve Spor Yüksekokulu, Tekirdağ. Türkiye

E-posta: atuncel@nku.edu.tr
Geliş Tarihi (Received): 18.07.2018 Kabul Tarihi (Accepted): 25.04.2019

\section{öz}

Bu araştırmanın amacı kaleci faktörünün futbolda penaltı vuruşunun kinematikleri üzerine etkilerini incelemekti. Araştırmaya profesyonel futbol oynamış 1 kaleci ve 5 futbolcu gönüllü olarak katıldı. Kale üzerinde belirlenmiş hedeflere kalede kaleci varken (kalecili) ve yokken (kalecisiz) yapılan isabetli vuruşlar incelendi. Kalecili ve kalecisiz vuruşlar ile temas öncesi ve sonrası arasındaki kinematik farklılıklar tekrarlayan ölçümlerde varyans analizi (ANOVA) ile karşılaştırıldı. Antropometrik noktaların hızları kalecili ve kalecisiz vuruşlarda farklıık göstermezken, hedeflere göre anlamlı farklıııklar göstermiştir $(p<.05)$. Kalecisiz sağ üst köşeye yapılan vuruşlarda topun yana ( $Z$ ekseni) hızının kalecili vuruşa göre daha yüksek olduğu bulunmuştur $(p<.05)$. Kalça eklemi hariç tüm antropometrik noktaların top temas öncesi ve sonrası hızlarında anlamlı farklılıklar bulunmuştur $(p<.05)$. Alt bacak ve ayak üyelerinin kütle merkezlerinin doğrusal hızlarında hedef faktörlerine göre anlamlı farklılıklar bulunmuştur $(p<.05)$. Alt bacak ve ayak üyeleri kütle merkezlerinin topa temas öncesi öne doğrusal hızı topa temas sonrasından yüksek bulunmuştur. Diz ve ayak bileği eklem açıları ve açısal hızlarının kalecili ve kalecisiz vuruşlarda hedef faktörlerine göre anlamlı farklııkların olduğu tespit edilmiştir $(p<.05)$. Sonuç olarak kalede kaleci olmasının penaltı vuruşunun kinematiğini etkilemediği, buna karşın hedefin topa vuruş kinematiği üzerinde önemli bir etkisinin olduğu belirlenmiştir.

Anahtar Kelimeler: Biyomekanik, Ayak içi vuruş, Hedef

\section{ABSTRACT}

The purpose of the study was to examine the effects of goalkeeper factor on the kinematics of the penalty kicking in soccer. Five professional players and one goalkeeper voluntarily participated in the study. Accurate penalty shots to fixed targets without and with goalkeeper in goalpost were analysed. Differences between penalty shots performed without and with goalkeeper were compared using a repeated measures analysis of variance (ANOVA). Although no significant difference was found in velocity of anthropometric landmarks for penalty shots with or without goalkeeper, significant differences were found with regard to targets $(p<.05)$. The linear horizontal velocity of the ball ( $Z$ axis) were significantly greater in penalty shots to right top corner without goalkeeper than that of right top corner with goalkeeper $(p<.05)$. The linear velocities of anthropometric landmarks except hip were found to be significantly different when before and after contact were evaluated. Significant differences were found with regard to target factor in linear velocity of the center of mass of lower leg and foot $(p<.05)$. The forward linear velocity of the center of mass of lower leg and foot was significantly greater before contact than after contact $(p<.05)$. Knee and ankle joint angles and angular velocities were found to change significantly due to target $(p<.05)$. Consequently, it was revealed that the kinematics of penalty kicking was not affected by existence of the goalkeeper in goalpoast, however, the target of the kick resulted in a significant change in the kinematics of the penalty kicking.

Key Words: Biomechanics, Inside kicking, Target 


\section{GíRIŞ}

Futbol şampiyonalarında ve çift ayaklı turnuva maçlarında kazananın belirlenmesi bazen seri penaltı atışları ile mümkün olmaktadır. Sezon içerisinde de oynanan müsabakalarda penaltı vuruşları önemli bir yer teşkil etmektedir. Bugüne kadar Dünya Futbol Şampiyonalarında oynanan toplam 836 maçta atılan 2379 golün 175'i penaltı vuruşlarından elde edilmiş̧ir (Fédération Internationale de Football Association [FIFA], 2016). Avrupa Futbol Şampiyonasında grup aşamalarının uygulanmaya başlandığı 1980 yılından itibaren oynanan 216 maçta atılan 518 golün 37 tanesi penaltı vuruşlarından kaydedilmiştir (Union of European Football Associations)[UEFA], 2016b). Avrupa Şampiyonlar Liginde (AŞL) oynanan son 22 sezon içerisinde çeyrek final, yarı final ve final maçlarında 286 maçta toplam 69 kez penaltı atışı kullanılırken bunlardan 50 tanesi gol ile sonuçlanmış, son 22 final karşılaşmasının 7'sinin kazananı seri penaltı atışları ile belirlenmiştir (UEFA 2016a). Yine Türkiye Profesyonel 1. Lig, 2. Lig ve 3. Liglerde bir üst lige çıkma müsabakalarında 2007/2008 sezonundan beri uygulanan statüde turu geçecek takımı belirlemek için oynanan 150 karşılaşmadan 33 tanesinde kazanan seri penaltı atışları sonucunda belirlenmiştir (Türkiye Futbol Federasyonu [TFF], 2016a, TFF, 2016b, TFF, 2016c).

Hedefe atılan isabetli pas, kaleye atılan şut ve penaltı vuruşu özel bir teknik gerektirir (Bauer, 1993; Bing ve diğ., 2012). Literatürde futbolda beceri isteyen vuruşlar kinetik ve kinematik açıdan incelenmiş, öne çıkan faktörler vurgulanırken (Bauer, 1993; Lees ve Nolan 2001; Hong ve diğ., 2013, Katis ve diğ., 2013) literatürde penaltı vuruşlarında kalecinin varlığının vuruş bacağının kinematiği üzerine sınırlı sayıda çalışmaya rastlanmıştır. Penaltı atışında atışı kullanan oyuncu kaleciye göre daha avantajı konumdadır çünkü oyuncunun vuruşu kalenin neresine yapacağı belli değildir. Buna karşın kalecilerin penaltıyı kullanacak oyuncunun hareketlerine bakarak vuruşu hangi köşeye ve nasıl kullanacağını kestirmeye çalışması atışı kullanan oyuncuyu baskı altına sokar (Diaz ve diğ., 2012; Murgia ve diğ., 2014). Penaltı vuruşunda bazı oyuncuların kalecinin hareketini izleyip, kalecinin hareketine göre vuruş yaparken, bazı oyuncular kale kösselerine veya merkeze daha yakın şiddetli vuruşlar yapmaktadırlar (Timmis ve diğ., 2014). Kaleci faktörünün topa vuruş sırasındaki biyomekanik değişkenler üzerinde etkilerini gösteren sınırlı sayıdaki çalışmada (Dicks ve diğ, 2010; Diaz ve di ̌̆, 2012; Katis ve diğ, 2013; Wood ve Wilson, 2012) kalecinin hareketleri (Weigelt ve Memmert, 2012) ve kaleci hareketlerinin psikolojik etkileri değerlendirilmiş (Navarro ve diğ., 2013a), değerlendirmenin yanında isabetli ve isabetsiz vuruş analizleri yapılmıştır (Navarro ve diğ., 2013b). Navarro ve diğ. (2013b) penaltı vuruşunda kalecili ve kalecisiz yapılan vuruşların isabet oranına etkisini inceledikleri çalışmada kalecili yapılan vuruşlarda kalecisiz yapılan vuruşlara göre daha düşük isabet oranı bildirmişlerdir. Weigelt ve Memmert (2012) kalecinin gol çizgisi üzerinde tam orta noktada durmadığında ve kalenin bir köşesini \%3 ve üzerinde açık bıraktığında futbolcuların açık köşeye vurmayı tercih ettiklerini bildirmişlerdir.

Penaltı atışında vuruşun gol olup olmaması kalecinin ve penaltıyı kullanan oyuncunun becerisi ile yakından ilgilidir. İnsanlar karşısındaki kişinin ne yapacağını onun vücut hareketlerine bakarak değerlendirebilir. Gol olma ihtimali yüksek olan penaltı gibi vuruşlarda kalecinin vuruşu yapan oyuncu üzerinde baskı oluşturması atışı yapan oyuncunun normalden daha farklı bir teknikle vurmasına neden olabilmektedir (Dicks ve diğ, 2010; Diaz ve diğ, 2012; Katis ve di Navarro ve diğ, 2013a; Navarro ve diğ, 2013b; Wood ve Wilson, 2012). Bu muhtemel teknik değişikliklerin incelenmesi penaltı vuruşunda gol oranını artırmaya yönelik önemli bilgilerin edinilmesini sağlayacaktır. Vuruşu yapan oyuncular kalecinin bulunduğu merkez noktadan ziyade kalenin iki köşe direğine yakın kalecinin uzanamayacağı bölgelere vurmayı tercih etmektedirler (Van der Kamp 2006, Weigelt ve Memmert (2012). Bu yüzden çalışmada kaleci faktörünün penaltı vuruşunun kinematikleri üzerindeki etkilerini ve olası değişimleri incelemek, kale içinde belirlenen hedeflere yapılan vuruşlarda kaleci faktörünün vuruşun kinematiklerine etkisini tespit etmek amaçlanmıştır. 


\section{YÖNTEM}

Katılımeılar: Araştırmaya oynadıkları takımlarında seri penaltı atışı olduğunda ilk beş isim arasına yazılan dominant bacağ1 sağ bacak olan beş futbolcu (yaş ortalaması: $26 \pm 2.97$ y1l, boy uzunluğu ortalaması: $181 \pm 6.04 \mathrm{~cm}$, vücut kütlesi ortalaması: $78.94 \pm 7.38 \mathrm{~kg}$, vücut kütle indeksi (VKİ) ortalamas1: $24.06 \pm 1.31 \mathrm{~kg} / \mathrm{m}^{2}$ ) ve bir kaleci (yaşı: 31 yıl, boy uzunluğu: 1.84 m, vücut kütlesi: $82.0 \mathrm{~kg}$, vücut kütle indeksi (VKI): $24.22 \mathrm{~kg} / \mathrm{m}^{2}$ ) katılmıştır. Tablo 1'de katılımcıların fiziksel özellikleri verilmiştir.

Tablo 1. Araştırmaya katılan futbolcuların fiziksel özellikleri.

\begin{tabular}{|c|c|c|c|c|c|c|c|c|}
\hline \multirow[b]{2}{*}{ Katılımcı } & \multirow[b]{2}{*}{ Cinsiyet } & \multirow[b]{2}{*}{$\begin{array}{l}\text { Yaş } \\
\text { (yil) }\end{array}$} & \multirow[b]{2}{*}{$\begin{array}{l}\text { Boy } \\
\text { (m) }\end{array}$} & \multirow[b]{2}{*}{$\begin{array}{c}\text { Vücut } \\
\text { kütlesi } \\
(\mathbf{k g})\end{array}$} & \multirow[b]{2}{*}{$\underset{\left(\mathbf{k g} / \mathbf{m}^{2}\right)}{\mathbf{V K I}}$} & \multicolumn{3}{|c|}{$\begin{array}{c}\text { Uzunluk } \\
\text { (cm) }\end{array}$} \\
\hline & & & & & & Üst Bacak & Alt Bacak & Ayak \\
\hline 1 & E & 23 & 1.73 & 71.0 & 23.72 & 45.0 & 34.0 & 18.5 \\
\hline 2 & E & 24 & 1.90 & 88.0 & 24.38 & 45.5 & 43.0 & 20.0 \\
\hline 3 & E & 25 & 1.81 & 85.0 & 25.95 & 43.0 & 40.0 & 19.0 \\
\hline 4 & E & 28 & 1.80 & 77.6 & 23.95 & 45.0 & 38.0 & 18.0 \\
\hline 5 & $\mathrm{E}$ & 25 & 1.81 & 73.1 & 22.31 & 38.5 & 42.5 & 15.5 \\
\hline $6(\mathrm{~K})$ & E & 31 & 1.84 & 82.0 & 24.22 & 46.0 & 42.0 & 20.0 \\
\hline
\end{tabular}

K: Kaleci

Veri Toplama Araçları: Penaltı vuruşlarının görüntüleri 2 adet yüksek hızlı kamera (Photron model SA3, 120K, JP) ve 1 adet dizüstü bilgisayar (Dell D630, ABD) vasıtasıyla kaydedilmiştir. Kayıtlı görüntülerin sayısallaştırma işlemlerinde HUBAG (Hacettepe Üniversitesi Biyomekanik Araştırma Grubu) hareket analizi yazılımı kullanılmıştır (Arıtan ve diğ., 2010). Her katılımcının antropometrik noktalarının belirlenmesi için 5 adet 12,7 mm çapında renkli işaretleyici, üyeler arasındaki uzunluğu ölçmek için FISCO marka mezura kullanılmıştır. Penaltı atışlarında FIFA onaylı, uluslararası maç standartlarına uygun 5 numara 410-430 gr ağırlığında, 9 atmosferik basınçlı Puma marka futbol topu kullanılmıştır.

Verilerin Toplanması/İşlem Yolu: Penaltı vuruşlarından önce futbolcuların sağ alt ekstremitesi üzerindeki beş antropometrik noktaya (kalça, diz, ayak bileği, topuk, ayakucu) ve bir tanede top üzerine renkli işaretleyici yerleştirilmiştir (Tablo 2). Futbolcuların sağ alt ekstremite üye uzunlukları (üst bacak, alt bacak ve ayak) renkli işaretleyicilerin arası dikkate alınarak mezura ile ölçülmüştür (Tablo 2).

Tablo 2. Yansıtıcı işaretlerin konulduğu noktalar ve tanımları.

\begin{tabular}{cll}
\hline No & İşaretlenen Antropometrik Nokta & Tanım \\
\hline 1 & Kalça & Femur kemiğinin proximal ucu (femur başı) \\
2 & Diz & Femur ve tibia birleşimi orta noktası \\
3 & Bilek & Tibia kemiğinin distal ucu (lateral malleol) \\
4 & Topuk & Calcenous kemiğinin lateral anteriör yanı \\
5 & Ayak ucu & 5. metatarsalın proksimal ucu lateral kısmı \\
6 & Top & Topun merkezi \\
\hline
\end{tabular}


Penaltı vuruşunun yapıldığı kalede Şekil 1'de belirlenen ölçülerde dört hedef belirlenmiştir. İlk turda beş futbolcudan ikisi kalede kaleci varken (kalecili), üçü ise kalede kaleci yokken (kalecisiz) isabetli penaltı vuruşları gerçekleştirmiştir. İkinci turda ise ilk turda kalecili vuruş yapanlar kalecisiz, kalecisiz vuruş yapanlar da kalecili olarak vuruşlarını yapmıştır. Futbolcular $2.5 \mathrm{~m}$ mesafeden istedikleri açıda topa yaklaşmış, rastgele arzu ettikleri hedefe sağ ayakları ile kalede kaleci varken ve kaleci yokken ayak içi vuruş gerçekleştirmişlerdir. Futbolculara vuruşlar arasında 3 dakika dinlenme verilmiştir. Hedefe yapılan isabetli vuruşların görüntüleri kaydedilmiştir. İsabetsiz vuruşlarda diğer katılımcı vuruş gerçekleştirmiş, isabetsiz vuruş yapan katılımcı diğer katılımcıdan sonra tekrar vuruş gerçekleştirmiştir. Penaltı vuruşları bittikten sonra hareketin gerçekleştiği alana metrik olarak uzaysal konumları bilinen sekiz noktalı kalibrasyon kafesi yerleştirilmiş ve görüntüsü kaydedilmiştir. Vuruşlar birbirine senkronize edilmiş ve pozlama hızı 1/10000 s, görüntü yakalama hızı saniyede 2000 kare olarak ayarlanan 2 adet yüksek hızlı kamera (Photron, SA3, 120K, JP) kullanılarak Gigabit Ethernet veri transfer kablosu ile bilgisayar ortamına aktarılmış ve Photron FASTCAM Viewer (Rev.2.41 English version) programı ile JPG formatında kaydedilmiştir. İki kameranın eşzamanlı kayda başlaması için kameralara bağlanan kablolar bir tetik (trigger) düzeneğine bağlanmış ve bu tetiğe basıldığında iki kamera aynı anda kayda başlamıştır. Kamera 1 ceza sahası yayı üzerinde kamera 2'ye 4.15 m diyagonal uzaklıkta ceza sahası yayı üzerinde $0.85 \mathrm{~m}$ yükseklikte konumlandırılmış, kamera 2 ise ceza sahası yayının bitiş noktasından $1.12 \mathrm{~m}$ sağında 1.03 m yüksekliğinde konumlandırılmıştır (Şekil 1).

Antropometrik noktaların sayısallaştırma işlemleri HUBAG hareket analizi yazılım kullanılmış ve noktaların piksel konum verisi elde edilmiştir. Antropometrik noktaların piksel konum verisi metrik 3 boyutlu (3B) konum verisine (X ekseni: yatay (ön-arka), Y ekseni: dikey ve Z ekseni: yana (sağa-sola)) Düzgün Doğrusal Dönüşüm algoritmas1 kullanılarak dönüştürülmüştür (Abdel-Aziz ve Karara 1971). Antropometrik noktalara ait 3B koordinatlar hesaplandıktan sonra bu koordinat değerlerine Python programlama dilinde yazılan filtreleme programı kullanılarak birinci dereceden kesme frekansı $48 \mathrm{~Hz}$ olan iki yönlü alçak-geçiren Butterworth filtre uygulanmıştır. Filtrelenmiş veriye Python'da yazılan en uygun polinomiyal değerine bağlı kalınarak elle sayısallaştırılan verilerin tam temsili için 5 ve 6'ncı dereceden polinom uydurulmuştur. En iyi polinom değerleri $\mathrm{R}^{2}>0.60$ ve üzeri uydurulup veriler işlenmiştir. Alt ekstremite üye kütle merkezleri Dempster'in vücut üye parametre değerleri kullanılarak hesaplanmıştır (Robertson ve diğ., 2004). Elde edilen veriler 1şığında vuruşların kinematik hesaplamaları (antropometrik nokta hızları ve üye kütle merkezi hızları) Python programlama dilinde yazılan kodlar kullanılarak yapılmıştır. Hesaplamalarda topla temas anı, temas süresi ve top çıkış süresi değerlendirmeye alınmıştır. Temas anı ayak üyesinin topa temas ettiği an, temas süresi ayağın topla temas ettiği süre ve temas sonrası ise topun ayaktan çıktığı an olarak alınmıştır. 


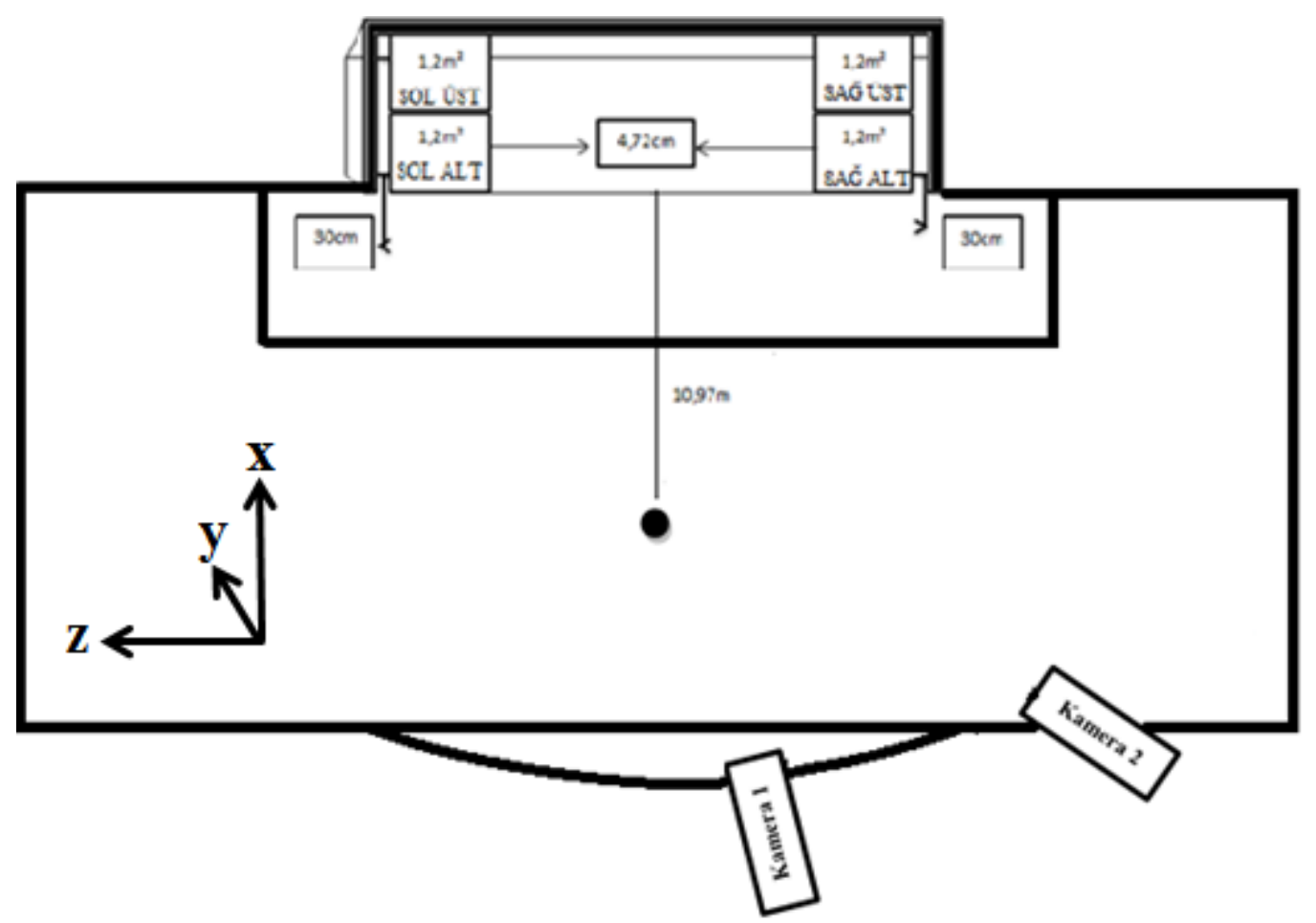

Şekil 1. Deney düzeneğinde kameraların ve kalede belirlenen hedeflerin yerleşimi.

Verilerin Analizi: Ortalama ve standart sapmaları hesaplanan verilerin normal dağılım gösterip göstermediği Kolmogorov-Smirnov testi ile analiz edilmiştir. Normal dağılım gösteren veriler 3 faktörlü Hedef (4: Sağ alt, sağ üst, sol alt ve sol üst köşeler), Kaleci (2: Kalecili, kalecisiz), Temas (2: Topa temas öncesi ve temas sonras1) (4x2x2) tekrarlayan ölçümlerde varyans analizi (ANOVA) ile karşılaştırılmıştır. Bonferroni düzeltmesi post-hoc test olarak kullanılmıştır. Kinematik değişkenlerde kalecili ve kalecisiz ile temas öncesi ve sonrası arasında farklılıklar eşleştirilmiş gruplarda t testi ile analiz edilmiştir. Anlamlılık düzeyi 0.05 kabul edilmiştir.

\section{BULGULAR}

Kalecili ve kalecisiz hedefe atılan penaltı vuruşlarında topa temas öncesi ve sonrası vuruş bacağındaki antropometrik noktaların ve topun anlık doğrusal hız değişimlerinin (X, Y ve Z eksenleri) istatistiksel analizi Tablo 3’te sunulmuştur.

Penaltı vuruşunda ayakucunun öne, dikey ve yana (X, Y, Z ekseni) doğrusal hızlarında hedef ( $\operatorname{sirasıyla;~} F_{(3,12)}=22.06$, $\left.\mathrm{F}_{(3,12)}=7.37, \mathrm{~F}_{(3,12)}=84.86 \mathrm{p}<.05\right)$ ve temas (sırasıyla; $\mathrm{F}_{(1,4)}=879.65, \mathrm{~F}_{(1,4)}=138.01, \mathrm{~F}_{(1,4)}=24.79$, $\mathrm{p}<.05$ ) faktörleri açısından anlamlı farklılıklar tespit edilirken ( $\mathrm{p}<.05)$, kaleci faktörü açısından anlamlı fark tespit edilmemiştir ( $\mathrm{p}>.05)$. Ayak bileği ekleminin öne ve yana doğrusal hızlarında hedef ( $\left.\mathrm{F}_{(1,4)}=169.07, \mathrm{~F}_{(1,4)}=12.70, \mathrm{p}<.05\right)$ faktörleri açısından anlamlı farklılıklar tespit edilirken $(\mathrm{p}<.05)$, kaleci faktörü açısından anlamlı bir fark tespit edilmemiştir $(\mathrm{p}>.05)$. Ayak bileği ekleminin dikey doğrusal hızında ise temas $\left(\mathrm{F}_{(1,4)}=8.27, \mathrm{p}<.05\right)$ faktörü açısından anlamlı fark tespit edilmiş, hedef ve kaleci faktörleri açısından anlamlı fark tespit edilmemiştir ( $\mathrm{p}>.05$ ). Diz ve kalça eklemi öne ve dikey doğrusal hızlarında hedef, kaleci ve temas faktörüne göre anlamlı farklılık tespit edilmezken ( $\mathrm{p}>$.05) diz eklemi yana doğrusal hızlarında temas faktörüne göre anlamlı farklılık tespit edilmiştir $\left(F_{(1,4)}=17.97, p<.05\right)$. Kalça ekleminin yana doğrusal hızında temas faktörüne göre anlamlı farklılık tespit edilmemiştir ( $\mathrm{p}>$.05). Topun öne ve dikey doğrusal hızlarında hedef ve kaleci faktörlerine göre anlamlı farklılık bulunmazken yana doğrusal hızında hedef $\left(\mathrm{F}_{(3,12)}=54.78, \mathrm{p}<.05\right)$ ve kaleci $\left(\mathrm{F}_{(1,4)}=14.52, \mathrm{p}<.05\right)$ faktörleri açısından anlamlı bir farklılık tespit edilmiştir. 
Tablo 3. Antropometrik noktaların hedeflere göre ortalama hızları.

\begin{tabular}{|c|c|c|c|c|c|c|c|c|c|c|c|c|}
\hline \multirow[b]{3}{*}{ Ayakucu } & \multicolumn{4}{|c|}{ X Ekseni Hız (m/s) } & \multicolumn{4}{|c|}{ Y Ekseni Hız (m/s) } & \multicolumn{4}{|c|}{ Z ekseni Hız (m/s) } \\
\hline & \multicolumn{2}{|c|}{ Kalecili } & \multicolumn{2}{|c|}{ Kalecisiz } & \multicolumn{2}{|c|}{ Kalecili } & \multicolumn{2}{|c|}{ Kalecisiz } & \multicolumn{2}{|c|}{ Kalecili } & \multicolumn{2}{|c|}{ Kalecisiz } \\
\hline & $\begin{array}{c}\text { Temas } \\
\text { öncesi } \\
\text { Ort } \pm \text { Ss }\end{array}$ & $\begin{array}{c}\text { Temas } \\
\text { Sonrasi } \\
\text { Ort } \pm \text { Ss }\end{array}$ & $\begin{array}{c}\text { Temas } \\
\text { öncesi } \\
\text { Ort } \pm \text { Ss }\end{array}$ & $\begin{array}{c}\text { Temas } \\
\text { Sonrası } \\
\text { Ort } \pm \text { Ss }\end{array}$ & $\begin{array}{l}\text { Temas } \\
\text { öncesi } \\
\text { Ort } \pm \text { Ss }\end{array}$ & $\begin{array}{l}\text { Temas } \\
\text { Sonrası } \\
\text { Ort } \pm \text { Ss }\end{array}$ & $\begin{array}{l}\text { Temas } \\
\text { öncesi } \\
\text { Ort } \pm \text { Ss }\end{array}$ & $\begin{array}{l}\text { Temas } \\
\text { Sonrasi } \\
\text { Ort } \pm \text { Ss }\end{array}$ & $\begin{array}{l}\text { Temas } \\
\text { öncesi } \\
\text { Ort } \pm \text { Ss }\end{array}$ & $\begin{array}{l}\text { Temas } \\
\text { Sonrası } \\
\text { Ort } \pm \text { Ss }\end{array}$ & $\begin{array}{l}\text { Temas } \\
\text { öncesi } \\
\text { Ort } \pm \text { Ss }\end{array}$ & $\begin{array}{l}\text { Temas } \\
\text { Sonrası } \\
\text { Ort } \pm \text { Ss }\end{array}$ \\
\hline Sağ alt köşe & $13.86 \pm 1.25^{\$}$ & $10.48 \pm 1.00$ & $14.53 \pm 0.94^{\$}$ & $10.48 \pm 1.00$ & $0.73 \pm 0.45$ & $2.43 \pm 0.95 \#$ & $1.12 \pm 0.39$ & $2.51 \pm 0.92$ & $6.79 \pm 2.46 \mathbf{q}^{\$}$ & $4.09 \pm 1.57 \S$ & $8.69 \pm 1.69 \|^{\$}$ & $6.02 \pm 1.749$ \\
\hline Sağ üst köşe & $14.20 \pm 1.00^{\$}$ & $10.74 \pm 1.14$ & $14.60 \pm 1.02^{\$}$ & $10.39 \pm 1.43$ & $1.00 \pm 0.88$ & $3.16 \pm 1.31^{\#}$ & $0.83 \pm 0.21$ & $3.55 \pm 1.34 \pi$ & $7.74 \pm 3.48 q^{\$}$ & $4.87 \pm 2.26^{\S}$ & $9.07 \pm 0.85 \boldsymbol{q}^{\$}$ & $5.47 \pm 0.75$ व \\
\hline Sol alt köşe & $17.80 \pm 1.41 * \$$ & $12.35 \pm 2.57$ & $17.73 \pm 0.92^{\# \$}$ & $13.36 \pm 1.03^{\#}$ & $1.73 \pm 1.02$ & $5.35 \pm 0.97 * \#$ & $1.43 \pm 0.79$ & $4.70 \pm 1.48 \#$ & $3.98 \pm 2.01 \$$ & $1.46 \pm 0.95$ & $2.97 \pm 1.64^{\$}$ & $1.39 \pm 0.52$ \\
\hline Sol üst köşe & $16.69 \pm 1.60^{\$}$ & $11.91 \pm 0.53$ & $17.20 \pm 2.01^{\$}$ & $13.34 \pm 1.18$ & $1.28 \pm 0.77$ & $4.43 \pm 1.10^{\#}$ & $1.68 \pm 1.34$ & $4.70 \pm 2.13 \#$ & $3.13 \pm 1.81 \$$ & $0.88 \pm 0.70$ & $2.49 \pm 2.53$ & $1.24 \pm 0.40$ \\
\hline \multicolumn{13}{|l|}{ Ayak bileği } \\
\hline Sağ alt köşe & $14.61 \pm 1.41^{\$}$ & $12.08 \pm 1.23$ & $14.49 \pm 0.87^{\$}$ & $12.12 \pm 1.09$ & $1.53 \pm 0.57$ & $1.27 \pm 1.16$ & $1.01 \pm 1.15$ & $1.41 \pm 0.78$ & $6.17 \pm 2.93$ & $4.64 \pm 1.77^{\S}$ & $6.64 \pm 2.23$ & $6.19 \pm 1.459$ \\
\hline Sağ üst köşe & $13.81 \pm 0.46^{\$}$ & $11.42 \pm 0.92$ & $14.36 \pm 0.89^{\$}$ & $12.15 \pm 1.17$ & $1.08 \pm 1.10$ & $1.62 \pm 0.63$ & $1.37 \pm 1.00$ & $2.16 \pm 1.10$ & $6.86 \pm 3.14 \rrbracket^{\$}$ & $4.83 \pm 2.179$ & $8.26 \pm 0.50 \rrbracket^{\$}$ & $5.83 \pm 0.60$ व \\
\hline Sol alt köşe & $16.33 \pm 1.09^{\$}$ & $13.24 \pm 2.05$ & $16.38 \pm 0.46^{\ddagger}$ & $13.77 \pm 0.72$ & $0.81 \pm 0.42$ & $3.00 \pm 0.92 \#$ & $1.01 \pm 0.87$ & $2.56 \pm 1.10$ & $3.75 \pm 2.01^{\$}$ & $1.35 \pm 1.17$ & $2.62 \pm 1.62$ & $1.22 \pm 0.67$ \\
\hline Sol üst köşe & $16.05 \pm 1.65^{\$}$ & $13.46 \pm 1.50$ & $16.05 \pm 1.89^{\$}$ & $13.30 \pm 1.82$ & $0.76 \pm 0.41$ & $2.64 \pm 1.12 \#$ & $1.02 \pm 0.51$ & $0.51 \pm 0.54$ & $2.51 \pm 1.97^{\$}$ & $0.51 \pm 0.54$ & $2.77 \pm 2.20$ & $0.96 \pm 0.33$ \\
\hline \multicolumn{13}{|l|}{$\overline{D i z}$} \\
\hline Sağ alt köşe & $5.22 \pm 1.57$ & $5.11 \pm 1.33$ & $5.31 \pm 1.27$ & $5.02 \pm 1.54$ & $1.43 \pm 0.69$ & $1.96 \pm 1.01^{\#}$ & $1.45 \pm 0.64$ & $1.96 \pm 0.25$ & $0.64 \pm 0.37$ & $1.22 \pm 0.23^{\$}$ & $0.35 \pm 0.37$ & $0.71 \pm 0.33$ \\
\hline Sağ üst köşe & $5.00 \pm 1.09$ & $4.73 \pm 0.89$ & $4.55 \pm 1.31$ & $4.62 \pm 1.45$ & $1.29 \pm 0.17$ & $1.37 \pm 0.46$ & $1.32 \pm 0.58$ & $1.97 \pm 0.37 \#$ & $0.81 \pm 0.25$ & $1.24 \pm 0.43^{\$}$ & $0.25 \pm 0.18$ & $0.74 \pm 0.50$ \\
\hline Sol alt köşe & $4.56 \pm 1.28$ & $4.46 \pm 1.50$ & $4.22 \pm 1.41$ & $3.90 \pm 1.43$ & $1.28 \pm 1.10$ & $1.47 \pm 1.22$ & $0.69 \pm 0.23$ & $1.23 \pm 0.57$ & $0.83 \pm 0.64$ & $1.39 \pm 0.82^{\$}$ & $1.17 \pm 0.63$ & $1.48 \pm 1.03$ \\
\hline Sol üst köşe & $3.84 \pm 1.15$ & $3.39 \pm 1.00$ & $4.04 \pm 1.20$ & $3.65 \pm 1.20$ & $0.67 \pm 0.70$ & $1.18 \pm 0.77 \#$ & $0.72 \pm 0.74$ & $1.08 \pm 0.71^{\#}$ & $0.96 \pm 0.50$ & $1.44 \pm 0.78^{\$}$ & $0.98 \pm 1.02$ & $1.40 \pm 1.11$ \\
\hline \multicolumn{13}{|l|}{ Kalça } \\
\hline Sağ alt köşe & $3.38 \pm 1.09$ & $3.25 \pm 1.00$ & $2.94 \pm 0.91$ & $2.74 \pm 1.14$ & $0.48 \pm 0.54$ & $0.60 \pm 0.69$ & $0.74 \pm 0.60$ & $0.82 \pm 0.85$ & $0.61 \pm 0.55$ & $0.88 \pm 0.61$ & $0.58 \pm 0.13$ & $0.37 \pm 0.38$ \\
\hline Sağ üst köşe & $2.85 \pm 0.77$ & $3.06 \pm 0.56$ & $2.40 \pm 1.43$ & $2.16 \pm 1.22$ & $0.37 \pm 0.34$ & $0.69 \pm 0.29$ & $0.47 \pm 0.59$ & $0.68 \pm 0.80$ & $0.59 \pm 0.49$ & $0.99 \pm 0.75$ & $0.57 \pm 0.34$ & $0.58 \pm 0.43$ \\
\hline Sol alt köşe & $2.63 \pm 0.85$ & $2.27 \pm 0.74$ & $2.16 \pm 0.93$ & $1.91 \pm 0.98$ & $0.32 \pm 0.06$ & $0.56 \pm 0.39$ & $0.55 \pm 0.38$ & $0.63 \pm 0.47$ & $0.59 \pm 0.50$ & $0.49 \pm 0.53$ & $0.42 \pm 0.54$ & $0.71 \pm 0.59$ \\
\hline Sol üst köşe & $1.94 \pm 1.08$ & $1.57 \pm 0.97$ & $2.26 \pm 0.95$ & $1.84 \pm 0.98$ & $0.30 \pm 0.30$ & $0.45 \pm 0.11$ & $0.27 \pm 0.27$ & $0.60 \pm 0.28$ & $0.37 \pm 0.30$ & $0.29 \pm 0.27$ & $0.76 \pm 0.60$ & $0.45 \pm 0.22$ \\
\hline \multicolumn{13}{|l|}{ Top } \\
\hline Sağ alt köşe & & $20.61 \pm 3.41$ & & $19.64 \pm 2.55$ & & $4.17 \pm 1.50$ & & $3.76 \pm 0.96$ & & $7.88 \pm 2.359$ & & $7.00 \pm 0.929$ \\
\hline Sağ üst köşe & & $19.30 \pm 3.32$ & & $21.17 \pm 2.06$ & & $5.91 \pm 0.96$ & & $6.56 \pm 0.4 *$ & & $6.70 \pm 1.429$ & & $8.90 \pm 0.63 \|^{\mathbf{P}}$ \\
\hline Sol alt köşe & & $24.68 \pm 4.61$ & & $23.35 \pm 2.23$ & & $4.97 \pm 1.71$ & & $3.44 \pm 1.31$ & & $2.86 \pm 2.31$ & & $2.56 \pm 0.80$ \\
\hline Sol üst köşe & & $22.59 \pm 4.16$ & & $22.48 \pm 6.46$ & & $6.48 \pm 1.08^{\#}$ & & $6.69 \pm 2.39$ & & $0.84 \pm 0.61$ & & $1.70 \pm 1.57$ \\
\hline $\begin{array}{l}{ }^{\#} \mathrm{p}<.05 \text { ayn } \\
+\mathrm{p}<.05 \text { ayn } \\
{ }^{*} \mathrm{p}<.05 \text { aynı }\end{array}$ & $\begin{array}{l}\text { unda sağ alt } \\
\text { anda sağ üst } \\
\text { anda sağ alt }\end{array}$ & $\begin{array}{l}\text { şeden farkl1 } \\
\text { şeden farklı } \\
\text { üst köşeden }\end{array}$ & trklı & 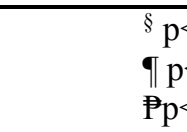 & $\begin{array}{l}05 \text { aynı si } \\
.05 \text { aynı s } \\
05 \text { kalecil }\end{array}$ & $\begin{array}{l}\text { da sol üst kö } \\
\text { da sol alt ve } \\
\text { ruştan farklı }\end{array}$ & $\begin{array}{l}\text { den farkl1 } \\
\text { st köşeden }\end{array}$ & arklı & & $\begin{array}{l}.05 \text { temas ör } \\
.05 \text { temas } \mathrm{sc}\end{array}$ & $\begin{array}{l}\text { icesinden far } \\
\text { onrasindan fa }\end{array}$ & $\begin{array}{l}\text { rkl1 } \\
\text { arklı }\end{array}$ \\
\hline
\end{tabular}


Tablo 4. Alt ekstremite üye kütle merkezlerinin üç boyutlu doğrusal hızları.

\begin{tabular}{|c|c|c|c|c|c|c|c|c|c|c|c|c|}
\hline \multirow[b]{3}{*}{ Üst bacak } & \multicolumn{4}{|c|}{ Öne (X ekseni) doğrusal hız (m/s) } & \multicolumn{4}{|c|}{ Dikey (Y Ekseni) doğrusal hız (m/s) } & \multicolumn{4}{|c|}{ Yana (Z ekseni) doğrusal hız $(\mathrm{m} / \mathrm{s})$} \\
\hline & \multicolumn{2}{|c|}{ Kalecili } & \multicolumn{2}{|c|}{ Kalecisiz } & \multicolumn{2}{|c|}{ Kalecili } & \multicolumn{2}{|c|}{ Kalecisiz } & \multicolumn{2}{|c|}{ Kalecili } & \multicolumn{2}{|c|}{ Kalecisiz } \\
\hline & $\begin{array}{c}\text { Temas } \\
\text { öncesi } \\
\text { Ort } \pm \text { Ss } \\
\end{array}$ & $\begin{array}{c}\text { Temas } \\
\text { Sonrasi } \\
\text { Ort } \pm \text { Ss } \\
\end{array}$ & $\begin{array}{c}\text { Temas } \\
\text { öncesi } \\
\text { Ort } \pm \text { Ss } \\
\end{array}$ & $\begin{array}{c}\text { Temas Sonrasi } \\
\text { Ort } \pm \text { Ss }\end{array}$ & $\begin{array}{c}\text { Temas } \\
\text { öncesi } \\
\text { Ort } \pm \text { Ss } \\
\end{array}$ & $\begin{array}{c}\text { Temas } \\
\text { Sonrasi } \\
\text { Ort } \pm \text { Ss } \\
\end{array}$ & $\begin{array}{c}\text { Temas } \\
\text { öncesi } \\
\text { Ort } \pm \text { Ss } \\
\end{array}$ & $\begin{array}{c}\text { Temas } \\
\text { Sonrasi } \\
\text { Ort } \pm \text { Ss } \\
\end{array}$ & $\begin{array}{c}\text { Temas } \\
\text { öncesi } \\
\text { Ort } \pm \text { Ss } \\
\end{array}$ & $\begin{array}{c}\text { Temas } \\
\text { Sonrası } \\
\text { Ort } \pm \text { Ss } \\
\end{array}$ & $\begin{array}{c}\text { Temas } \\
\text { öncesi } \\
\text { Ort } \pm \text { Ss } \\
\end{array}$ & \begin{tabular}{l|l} 
Temas \\
Sonrasi \\
Ort \pm Ss \\
\end{tabular} \\
\hline Sağ alt köşe & $4.22 \pm 1.03$ & $4.16 \pm 1.13$ & $3.91 \pm 1.29$ & $3.78 \pm 1.25$ & $0.78 \pm 0.50$ & $1.00 \pm 0.76$ & $1.11 \pm 0.41$ & $1.40 \pm 0.53$ & $0.57 \pm 0.38$ & $0.79 \pm 0.65$ & $0.26 \pm 0.19$ & $0.49 \pm 0.32$ \\
\hline Sağ üst köşe & $3.84 \pm 0.78$ & $3.81 \pm 0.73$ & $3.39 \pm 1.20$ & $3.28 \pm 1.03$ & $0.79 \pm 0.24$ & $0.91 \pm 0.41$ & $0.78 \pm 0.47$ & $1.19 \pm 0.57$ & $0.64 \pm 0.35$ & $1.11 \pm 0.52$ & $0.33 \pm 0.21$ & $0.33 \pm 0.30$ \\
\hline Sol alt köşe & $3.48 \pm 1.05$ & $3.25 \pm 1.07$ & $3.08 \pm 1.13$ & $2.79 \pm 1.20$ & $0.66 \pm 0.70$ & $0.95 \pm 0.75$ & $0.61 \pm 0.39$ & $0.92 \pm 0.39$ & $0.64 \pm 0.45$ & $0.92 \pm 0.59$ & $0.71 \pm 0.61$ & $0.88 \pm 0.93$ \\
\hline Sol üst köşe & $2.78 \pm 0.90$ & $2.37 \pm 0.79$ & $3.05 \pm 1.01$ & $2.66 \pm 1.00$ & $0.40 \pm 0.34$ & $0.81 \pm 0.34$ & $0.49 \pm 0.41$ & $0.73 \pm 0.47$ & $0.38 \pm 0.29$ & $0.79 \pm 0.32$ & $0.81 \pm 0.74$ & $0.89 \pm 0.61$ \\
\hline \multicolumn{13}{|l|}{ Alt bacak } \\
\hline Sağ alt köşe & $9.32 \pm 1.49^{\$}$ & $8.54 \pm 1.52$ & $9.06 \pm 1.36^{\$}$ & $8.12 \pm 0.94$ & $1.68 \pm 0.71$ & $0.94 \pm 0.82$ & $1.36 \pm 0.48$ & $0.57 \pm 0.48$ & $2.48 \pm 0.78^{\$}$ & $1.58 \pm 1.00$ & $3.41 \pm 0.71^{\text {st }}$ & $2.37 \pm 0.69$ \\
\hline Sağ üst köşe & $9.13 \pm 0.62^{\$}$ & $7.72 \pm 0.56$ & $9.15 \pm 0.98^{\$}$ & $8.09 \pm 1.27$ & $1.15 \pm 0.51$ & $0.34 \pm 0.14$ & $1.37 \pm 0.38$ & $0.32 \pm 0.31$ & $2.94 \pm 1.60 \$$ & $1.75 \pm 1.37$ & $3.93 \pm 0.43^{\text {st }}$ & $2.31 \pm 0.29$ \\
\hline Sol alt köşe & $9.84 \pm 1.31^{\$}$ & $8.46 \pm 1.42$ & $9.68 \pm 1.14^{\$}$ & $8.35 \pm 1.11$ & $0.94 \pm 0.63$ & $1.03 \pm 0.87$ & $0.95 \pm 0.54$ & $0.64 \pm 0.38$ & $1.31 \pm 1.14$ & $0.94 \pm 0.60$ & $0.95 \pm 0.39$ & $0.69 \pm 0.85$ \\
\hline Sol üst köşe & $9.36 \pm 0.86^{\$}$ & $7.95 \pm 0.69$ & $9.46 \pm 1.25^{\$}$ & $8.02 \pm 1.21$ & $0.65 \pm 0.44$ & $0.79 \pm 0.37$ & $0.82 \pm 0.26$ & $0.82 \pm 0.79$ & $0.73 \pm 0.86$ & $1.00 \pm 0.26$ & $1.37 \pm 0.77$ & $0.94 \pm 0.88$ \\
\hline \multicolumn{13}{|l|}{ Ayak } \\
\hline Sağ alt köşe & $14.62 \pm 0.96^{\$}$ & $12.24 \pm 1.51$ & $14.64 \pm 0.76^{\$}$ & $12.27 \pm 1.21$ & $1.95 \pm 2.34$ & $2.21 \pm 1.21$ & $0.72 \pm 0.81$ & $2.05 \pm 1.13$ & $6.58 \pm 1.45^{\$}$ & $5.07 \pm 2.13^{\mathrm{P}}$ & $8.48 \pm 1.58^{\$ \#}$ & $6.29 \pm 1.50 \#$ \\
\hline Sağ üst köşe & $14.27 \pm 1.05^{\$}$ & $11.64 \pm 1.35$ & $14.89 \pm 1.09^{\$}$ & $12.11 \pm 0.87$ & $0.81 \pm 0.89$ & $2.29 \pm 0.64$ & $0.74 \pm 0.93$ & $2.74 \pm 1.10$ & $7.52 \pm 3.51^{\$ \uparrow}$ & $5.23 \pm 2.23^{\mathbb{P}}$ & $8.99 \pm 0.37^{\text {\$H }}$ & $6.50 \pm 1.01^{\#}$ \\
\hline Sol alt köşe & $17.61 \pm 1.11^{\$ \S}$ & $13.44 \pm 2.13$ & $17.59 \pm 0.99^{\text {\$\# }}$ & $14.18 \pm 0.99^{\#}$ & $0.76 \pm 0.28$ & $4.09 \pm 0.83^{\dagger}$ & $0.62 \pm 0.67$ & $3.56 \pm 1.22^{\dagger}$ & $3.99 \pm 2.13^{\$}$ & $1.44 \pm 1.10$ & $2.98 \pm 1.92$ & $1.49 \pm 0.73$ \\
\hline Sol üst köșe & $16.91 \pm 1.79^{\$}$ & $13.39 \pm 1.31$ & $17.18 \pm 2.07^{\$}$ & $13.60 \pm 1.83$ & $0.42 \pm 0.34$ & $3.27 \pm 0.94^{\dagger}$ & $1.05 \pm 0.78$ & $3.51 \pm 1.52^{\dagger}$ & $2.98 \pm 2.02^{\$}$ & $0.55 \pm 0.73$ & $2.84 \pm 2.53$ & $1.20 \pm 0.35$ \\
\hline $\begin{array}{l}\$ \mathrm{p}<.05 \text { tema } \\
\dagger \mathrm{p}<.05 \text { temas } \\
+\mathrm{p}<.05 \text { aynı } \\
\# \mathrm{p}<.05 \text { aynı }\end{array}$ & $\begin{array}{l}\text { s sonrasından } \\
\text { öncesinden f } \\
\text { sütunda sağ ü } \\
\text { sütunda sağ a }\end{array}$ & $\begin{array}{l}\text { farklı } \\
\text { rklı } \\
\text { t köşeden an } \\
\text { t köşeden anl }\end{array}$ & $\begin{array}{l}\text { lamlı farklılık } \\
\text { amlı farklılık }\end{array}$ & & $\begin{array}{l}\$ \mathrm{p}<.05 \text { ay } \\
\# \mathrm{p}<.05 \text { a) } \\
\text { I } \mathrm{p}<.05 \text { ay } \\
\mathrm{Pp}<.05 \text { ay }\end{array}$ & $\begin{array}{l}1 \text { sütunda sa } \\
1 \text { sütunda } \mathrm{S} \\
1 \text { sütunda so } \\
\text { sütunda so }\end{array}$ & $\begin{array}{l}\text { alt ve üst } 1 \\
\text { alt ve üst } \\
\text { alt köşeder } \\
\text { üst köşeder }\end{array}$ & $\begin{array}{l}\text { öşeden anla } \\
\text { öşseden anla } \\
\text { anlamlı far } \\
\text { anlamlı far }\end{array}$ & $\begin{array}{l}\text { li fark } \\
\text { ll fark }\end{array}$ & & & \\
\hline
\end{tabular}


Tablo 4'te alt ekstremite üyelerinin kütle merkezlerinin doğrusal hızlarındaki değişimler verilmiştir.

Üst bacağın kütle merkezinin öne doğrusal hızında hedef $\left(\mathrm{F}_{(3,12)}=9.15, \mathrm{p}<0.05\right)$ faktörü açısından anlamlı farklılık olduğu, kaleci $\left(\mathrm{F}_{(1,4)}=2.66, \mathrm{p}>0.05\right)$ ve temas $\left(\mathrm{F}_{(1,4)}=4.54, \mathrm{p}>0.05\right)$ faktörleri açısından ise anlamlı farklılık olmadığ tespit edilmiştir. Üst bacağın kütle merkezinin dikey ve yana doğrusal hızlarında hedef, kaleci ve temas faktörlerine göre anlamlı farklılık tespit edilmemiştir ( $\mathrm{p}>.05)$.

Alt bacağın kütle merkezinin öne doğrusal hızı temas $\left(\mathrm{F}_{(1,4)}=335.29, \mathrm{p}<0.05\right)$ faktörü açısından anlamlı farklılık gösterirken, yana doğrusal hızda temas $\left(\mathrm{F}_{(1,4)}=12.58, \mathrm{p}<0.05\right)$ ve hedef $\left(\mathrm{F}_{(3,12)}=37.06, \mathrm{p}<0.05\right)$ faktörüne göre anlamlı farklılık gösterdiği tespit edilmiştir. Alt bacağın kütle merkezi dikey hızında tüm faktörler açısından anlamlı farklılık tespit edilmemiştir $(\mathrm{p}>.05)$.

Ayağın kütle merkezinin öne ve yana doğrusal hızı hedef (sırasıyla: $F_{(3,12)}=14.64, F_{(3,12)}=136.75$, $p<0.05$ ) ve temas $\left(\mathrm{F}_{(1,4)}=147.17, \mathrm{~F}_{(1,4)}=33.81, \mathrm{p}<0.05\right)$ faktörleri açısından anlamlı farklılık gösterirken, kaleci faktörü açısından anlamlı farklılık göstermemiştir. Dikey doğrusal hızda ise temas $\left(\mathrm{F}_{(1,4)}=56.45, \mathrm{p}>0.05\right)$ faktörü açısından anlamlı fark bulunurken, hedef $\left(\mathrm{F}_{(3,12)}=2.77, \mathrm{p}>0.05\right)$ ve kaleci $\left(\mathrm{F}_{(1,4)}=0.47, \mathrm{p}>0.05\right)$ faktörleri açısından anlamlı bir fark bulunmamıştır.

Üst bacak, alt bacak ve ayak üyelerinin kütle merkezlerinin öne ve dikey doğrusal hızında hedef-kaleci, hedef-temas, kaleci-temas ve hedef-kaleci-temas faktörlerinin etkileşimleri anlamlı bulunmamıştır. Alt bacak kütle merkezinin yana doğrusal hızında hedef-temas $\left(\mathrm{F}_{(3,12)}=6.55, \mathrm{p}<0.05\right)$ ve kaleci-temas $\left(\mathrm{F}_{(3,12)}=9.52, \mathrm{p}<0.05\right)$ faktörlerinin etkileşimi anlamlı bulunurken, hedef-kaleci $\left(\mathrm{F}_{(3,12)}=2.03, \mathrm{p}>0.05\right)$ ve hedef- kaleci-temas $\left(\mathrm{F}_{(3,12)}=0.80, \mathrm{p}>0.05\right)$ faktörlerinin etkileşimi anlamlı bulunmamıştır.

Tablo 5'te kalede kaleci varken sağ alt köşeye atılan penaltı vuruşunda ayağın topla temas süresinin daha yüksek olduğu tespit edilmiştir $\left(\mathrm{t}_{4}=2.90, \mathrm{p}<.05\right)$.

Tablo 5. Kalecili ve kalecisiz hedefe yapılan vuruşlarda topa temas süreleri.

\begin{tabular}{lcc}
\hline \multicolumn{1}{c}{ Temas süresi (s) } & $\begin{array}{c}\text { Kalecili } \\
\text { Ort } \pm \text { Ss }\end{array}$ & $\begin{array}{c}\text { Kalecisiz } \\
\text { Ort } \pm \text { Ss }\end{array}$ \\
\hline Să̆ alt köşe & $0.011 \pm 0.002^{*}$ & $0.009 \pm 0.002$ \\
Sağ üst köşe & $0.011 \pm 0.002$ & $0.011 \pm 0.005$ \\
Sol alt köşe & $0.013 \pm 0.008$ & $0.011 \pm 0.002$ \\
Sol üst köşe & $0.011 \pm 0.002$ & $0.011 \pm 0.002$ \\
\hline
\end{tabular}

$* \mathrm{p}<.05$ kalecisiz vuruştan farkl1

Tablo 6'da penaltı vuruşunda diz ve ayak bileği eklem açıları verilmiştir. Diz ekleminin açısı hedef $\left(\mathrm{F}_{(3,12)}=11.17\right.$, $\mathrm{p}<.05)$ ve temas $\left(\mathrm{F}_{(1,4)}=234.41, \mathrm{p}<.05\right)$ faktörlerine göre anlamlı farklılıklar gösterirken, ayak bileği eklem açısı hedefe $\left(\mathrm{F}_{(3,12)}=33.30, \mathrm{p}<.05\right)$ göre anlamlı farklılık göstermiştir. Diz eklem açısında faktörlerin etkileşimi anlamlı bulunmazken, hedef-temas faktörünün etkileşimi anlamlı bulunmuştur $\left(\mathrm{F}_{(3,12)}=12.42, \mathrm{p}<.05\right)$. Ayak bileği eklem açısında faktörlerin etkileşimi anlamlı bulunmamıştır.

Kalecisiz hedeflere yapılan tüm vuruşlarda temas öncesinde ve temas sonrasında ayak bileği eklem açısında anlamlı farklılıklar tespit edilmiş (sırasıyla, $\mathrm{F}_{(3,12)}=5.20$, $\mathrm{p}<.05, \mathrm{~F}_{(3,12)}=5.18, \mathrm{p}<.05$ ) ancak hedeflerin ikili karşılaştırmalarında anlamlı farklılık görülmemiştir. 
Tablo 6. Diz ve ayak bileği eklemlerinin temas öncesi ve sonrası anlık açısı.

\begin{tabular}{lcccc}
\hline & \multicolumn{3}{c}{ Eklem Açısı $\left(^{\circ}\right)$} \\
\cline { 2 - 5 } Diz & \multicolumn{2}{c}{ Kalecili } & Kalecisiz \\
\cline { 2 - 5 } & $\begin{array}{c}\text { Temas Öncesi } \\
\text { Ort } \pm \text { Ss }\end{array}$ & $\begin{array}{c}\text { Temas Sonrası } \\
\text { Ort } \pm \text { Ss }\end{array}$ & $\begin{array}{c}\text { Temas Öncesi } \\
\text { Ort } \pm \text { Ss }\end{array}$ & $\begin{array}{c}\text { Temas Sonrası } \\
\text { Ort } \pm \text { Ss }\end{array}$ \\
\hline Să̆ alt köşe & $146.03 \pm 13.58$ & $157.75 \pm 13.88$ & $147.58 \pm 14.07$ & $155.78 \pm 13.55$ \\
Sağ üst köşe & $150.23 \pm 10.61^{*}$ & $160.10 \pm 10.35^{\#}$ & $148.79 \pm 11.75$ & $159.90 \pm 8.90$ \\
Sol alt köşe & $137.80 \pm 9.04$ & $156.72 \pm 12.06$ & $130.60 \pm 10.32$ & $147.53 \pm 10.38$ \\
Sol üst köşe & $133.60 \pm 12.64$ & $150.49 \pm 9.41$ & $136.98 \pm 9.00$ & $154.52 \pm 6.01$ \\
\hline Ayak bileği & & & & $128.11 \pm 4.85$ \\
\hline Sağ alt köşe & $126.41 \pm 3.63^{\#}$ & $124.93 \pm 4.61^{\#}$ & $128.10 \pm 4.66$ & $131.99 \pm 2.16$ \\
Sağ üst köşe & $130.33 \pm 9.25$ & $129.97 \pm 9.49$ & $132.43 \pm 2.22$ & $133.80 \pm 6.52$ \\
Sol alt köşe & $136.07 \pm 3.05$ & $134.40 \pm 3.83$ & $134.41 \pm 5.80$ & $137.49 \pm 6.32$ \\
Sol üst köșe & $135.09 \pm 4.39$ & $134.86 \pm 5.11$ & $137.61 \pm 6.35$ & \\
\hline
\end{tabular}

${ }^{*} \mathrm{p}<.05$ aynı sütunda sol üst köşeden farklı

\# $\mathrm{p}<.05$ aynı sütunda sol alt ve üst köşeden farklı

${ }^{\uparrow} \mathrm{p}<.05$ aynı sütunda sol alt köşeden farklı

${ }^{\$} \mathrm{p}<.05$ temas sonradan farklı

Tablo 7'de penaltı vuruşunda diz ve ayak bileği eklemlerinin açısal hızı verilmiştir. Diz ekleminin açısal hızı hedef $\left(\mathrm{F}_{(3,12)}=14.40, \mathrm{p}<.05\right)$ faktörü açısından anlamlı farklılık tespit edilirken, temas $\left(\mathrm{F}_{(1,4)}=4.42, \mathrm{p}>.05\right)$ ve kaleci $\left(\mathrm{F}_{(1,4)}=0.12\right.$, p>.05) faktörleri açısından ise anlamlı fark tespit edilmemiştir. Ayak bileği ekleminin açısal hızı temas $\left(\mathrm{F}_{(1,4)}=71.33\right.$, $\mathrm{p}<.05)$ faktörü açısından anlamlı farklılık gösterirken, hedef $\left(\mathrm{F}_{(3,12)}=0.36, \mathrm{p}>.05\right)$ ve kaleci $\left(\mathrm{F}_{(1,4)}=0.12, \mathrm{p}>.05\right)$ faktörleri açısından ise anlamlı farklılık göstermemiştir. Diz ve ayak bileği ekleminin açısal hızında faktörlerin etkileşimleri anlamlı bulunmamıştır.

Tablo 7. Diz ve ayak bileği eklemlerinin açısal hızı.

\begin{tabular}{|c|c|c|c|c|}
\hline \multirow[b]{3}{*}{ Diz } & \multicolumn{4}{|c|}{ Açısal Hız $\left({ }^{\circ} \cdot s^{-1}\right)$} \\
\hline & \multicolumn{2}{|c|}{ Kalecili } & \multicolumn{2}{|c|}{ Kalecisiz } \\
\hline & $\begin{array}{c}\text { Temas Öncesi } \\
\text { Ort } \pm \text { Ss }\end{array}$ & $\begin{array}{c}\text { Temas Sonrası } \\
\text { Ort } \pm \text { Ss }\end{array}$ & $\begin{array}{c}\text { Temas Öncesi } \\
\text { Ort } \pm \text { Ss }\end{array}$ & $\begin{array}{c}\text { Temas Sonrası } \\
\text { Ort } \pm \text { Ss }\end{array}$ \\
\hline Sağ alt köșe & $1084.03 \pm 196.56^{\#}$ & $982.38 \pm 207.46$ & $923.61 \pm 224.33^{\#}$ & $819.17 \pm 368.76^{\natural}$ \\
\hline Sağ üst köşe & $1021.42 \pm 198.27^{\llbracket}$ & $911.07 \pm 159.35$ & $1154.28 \pm 204.50^{\natural}$ & $991.83 \pm 242.26$ \\
\hline Sol alt köșe & $1640.13 \pm 132.09$ & $1305.02 \pm 485.15$ & $1619.13 \pm 259.04$ & $1448.59 \pm 269.41$ \\
\hline Sol üst köşe & $1638.26 \pm 290.82$ & $1462.48 \pm 449.08$ & $1637.46 \pm 267.41$ & $1325.85 \pm 574.29$ \\
\hline \multicolumn{5}{|l|}{ Ayak bileği } \\
\hline Sağ alt köșe & $-118.13 \pm 278.83$ & $-176.32 \pm 205.50$ & $10.91 \pm 47.67$ & $-54.83 \pm 106.74$ \\
\hline Sağ üst köşe & $22.65 \pm 42.48$ & $-108.56 \pm 215.22$ & $26.09 \pm 46.04$ & $-165.97 \pm 44.95^{\$}$ \\
\hline Sol alt köșe & $41.35 \pm 108.74$ & $-243.07 \pm 145.55^{\$}$ & $6.31 \pm 73.22$ & $-155.61 \pm 164.60$ \\
\hline Sol üst köşe & $107.05 \pm 93.39$ & $-262.31 \pm 135.82^{\$}$ & $117.57 \pm 98.14$ & $-264.42 \pm 312.17$ \\
\hline \multicolumn{5}{|c|}{${ }^{*} \mathrm{p}<.05$ aynı sütunda sol üst köşeden farklı } \\
\hline \multicolumn{5}{|c|}{${ }^{\#} \mathrm{p}<.05$ aynı sütunda sol alt ve üst köşeden farklı } \\
\hline \multicolumn{5}{|c|}{${ }^{\natural} \mathrm{p}<.05$ aynı sütunda sol alt köşeden farklı } \\
\hline$\$ \mathrm{p}<.05$ tem & an farklı & & & \\
\hline
\end{tabular}




\section{TARTISSMA}

$\mathrm{Bu}$ çalışma, penaltı vuruşu sırasında belirlenen hedefe yapılan vuruşta kaleci varlığının vuruşun kinematiğini etkileyip etkilemediğini belirlemek amacıyla yapılmıştır. Kaleci varlığının top ve vuruş bacağının kinematiğini etkilemediği bulunurken, hedef faktörünün vuruşun kinematiği üzerinde etkili olduğu bulunmuştur.

Navarro ve diğ. (2013b) penaltı vuruşlarında kalecinin varlığının vuruşun doğruluğunu etkileyip etkilemediğini inceledikleri çalı̧̧mada kalenin sağ ve sol üst köşelerindeki $2.88 \mathrm{~m}^{2}$ lik iki hedefe kaleci varken yapılan vuruşların kaleci yokken yapılan vuruşlara göre kalecinin vurulacak hedefi bildiği için kalecinin varlığının yapılan vuruşların doğruluğunu olumsuz etkilediğini bildirmişlerdir. Kawamoto ve diğ. (2007) iç vuruşta ayak üyesinin hızının tecrübeli sporcularda $14.3 \pm 0.7 \mathrm{~m} . \mathrm{s}^{-1}$ tecrübesiz oyuncularda ise $11.5 \pm 0.8 \mathrm{~m} \cdot \mathrm{s}^{-1}$ olarak bildirmişler. Bir diğer çalışmada da kadın sporcuların ayak içi vuruşlarında ayak üye hızını $15.3 \pm 1.1 \mathrm{~m} . \mathrm{s}^{-1}$ olarak bildirmişlerdir (Sakamoto ve diğ., 2010). Zago ve diğ. (2014) iç vuruşta amatör futbolcuların üye kütle merkezlerinin doğrusal hızlarını üst bacak, alt bacak ve ayak için sırasıyla $1.64 \pm 0.39 \mathrm{~m} . \mathrm{s}^{-1}, 4.93 \pm 1.18 \mathrm{~m} \cdot \mathrm{s}^{-1}$ ve $10.2 \pm 0.65 \mathrm{~m} . \mathrm{s}^{-1}$ olarak bildirmiştir. Bu araştırmada elde edilen üyelerin doğrusal hızları Zago ve diğ. (2014)'nın çalışmasında ki verilerden daha yüksek bulunmuştur. Bu farklılık çalışmaya katılan futbolcuların tecrübe düzeyleri ve hedeflere net vuruşlar yapmak zorunda olmaları ile açıklanabilir. Bu yorumumuz Kawamato ve diğ (2007)'nın tecrübeli ve tecrübesiz oyuncuların vuruşlarını incelediği çalışmadaki bulguları ve Navarro ve diğ. (2013b)'nin hedef belirlemenin vuruşun doğruluğunu etkilediği yönünde bulgularıyla desteklenmektedir. Ayak ve alt bacak üyelerinin kütle merkezlerinin yataydaki hızları ise literatür ile benzerlik göstermiştir.

Topa vuruşta alt ekstremite kütle merkezlerinin hızı momentumun topa aktarabilmesi için oldukça önemlidir (Isokawa ve Lees, 1988; Kawamato ve diğ., 2007; Kellis ve Katis, 2007; Nunome ve diğ., 2002). Kuşkusuz ki topun hızını belirleyen en önemli parametrelerden biri ayağın top ile temas anındaki hızıdır (Kawamoto ve diğ., 2007; Kellis ve Katis, 2007; Nunome ve diğ., 2002). Navarro ve diğ. (2013b)'nin yaptıkları çalışmada bildirilen topun hız değerlerinin bu çalışmada bulunan topun hız değerlerine göre daha düşük olduğu gözlenmiştir. Bunun nedeninin hedeflerin daha küçük olması ve hedeflerin penaltı vuruşlarında kalecinin uzanamayacağı nokta olarak değerlendirilen kale direğinin $30 \mathrm{~cm}$ kenarına yerleştirilmesinden kaynaklandığı düşünülmektedir. Belirlenen hedefin kalecinin uzanabileceği bir alanda olması oyuncuyu baskıya sokarken yapılan vuruşun hızını dolayısıyla topun hızını arttırmaktadır. Üst bacak segmentinin topla temas süresince yapacağ dış-iç rotasyonlar ile birlikte ayağın topla temas ettiği bölge ve topla temas süresince üç boyuttaki ayak segmentinin hareketi topun gideceği yön, hız ve spinin belirleyicisi olacaktır (Kawamoto ve diğ., 2007, Kellis ve Katis, 2007; Nunome ve diğ., 2002). Belirlenen hedefe yapılan vuruşlarda hedeflerin değiş̧mesi vuruşun kinematiğinde de farklılıklar meydana getirecektir. Tecrübe kazanmış sporcuların veya çok fazla tekrar ile vuruş için gerekli beceriyi kazanmış oyuncuların antrenörler tarafından serbest atışları kullanmak için tercih edilmeleri bu açıdan önemlidir. Literatürde tecrübeli-tecrübesiz, kadın-erkek sporcuların topa vuruşlarının karşılaştırdığı çalışmalarda tecrübeli ve erkek sporcuların daha iyi sonuçlar elde etmesine ek olarak (Kawamoto ve diğ., 2007; Sakamoto ve diğ., 2012; Zago ve diğ., 2014) bu çalışmada hedef faktörü devreye girdiği şutlarda elde edilen sonuçlar vuruşun kinematiğinde meydana gelen farklılıkları ve antrenörlerin seçimlerini açıklamaktadır. Zago ve diğ. (2014) iç vuruşta amatör futbolcuların üst bacak, alt bacak ve ayak üye kütle merkezleri için sırasıyla $1.64 \pm 0.39 \mathrm{~m} . \mathrm{s}^{-1}, 4.93 \pm 1.18 \mathrm{~m} \cdot \mathrm{s}^{-1} \mathrm{ve}$ $10.2 \pm 0.65 \mathrm{~m} . \mathrm{s}^{-1}$ öne doğrusal hız, Kawamoto ve diğ. (2007) tecrübeli sporcularda iç vuruşta ayak üyesi hızının $14.3 \pm 0.7$ $\mathrm{m} . \mathrm{s}^{-1}$ tecrübesiz oyuncularda ise $11.5 \pm 0.8 \mathrm{~m} \cdot \mathrm{s}^{-1}$ olarak bildirmişler. Sakamoto ve diğ. (2012) hedefe yapılan farklı vuruş tekniklerinde top temas anında vuruş şekline göre ayak hızının değiştiğini, erkek futbolcuların ayak hızının kadın futbolculara göre daha hızlı olduğunu belirtmişlerdir. 
Yine topun yüksekliğini belirleyen ayağın toptan çıkış anında ayağın dikeydeki hızının topun dikey hareketine etki ettiği gözlenmiştir. Ayakucunun yana doğrusal hızının sol alt ve üst köşeye yapılan vuruşlarda, sağ alt ve üst köşelere yapılan vuruşlara göre daha yavaş olduğu gözlenmiştir. Bunun nedenini sağ ayaklı oyuncuların solunda olan hedeflere yaptıkları vuruşlarda topun hedefe gitmesi için topa spin vermeme zorunlulukları ve kalça-alt bacak-ayak rotasyonunun az olması sebebiyle açıklanabilir. Yine sol alt-üst köşeye yapılan vuruşlarda top temas anında ayakucunun üç eksende de doğrusal hızının sağ alt-üst köşeye yapılan vuruşlardan daha hızlı olması da bu sebeple açıklanabilir.

Ayağın top ile temas süresi vuruşun şiddetini belirleyici etmenlerinden bir tanesidir. Yapılan bu çalışmada top ile ayağın temas süresinin yaklaşık olarak 0.011 saniye gibi çok kısa bir süre olduğu gözlenmiştir. Kalecilerin penaltı atışlarında vuruş yapılana kadar beklemelerini içeren penaltı stratejisinin hedefe yapılacak net vuruşlara karşı etkisiz kalacağı top temas süresi ile açıklanabilir. Penaltı atışlarında kalecinin topa temastan önce ve sonra hareket etme stratejisinin incelendiği çalışmada kalecilerin erken hareket ettikleri durumlarda oyuncuların açık olan köşeye vurma eğilimi gösterdikleri belirtilmiştir (Noël ve diğ., 2015). Yapılan çalışmada kalecili ve kalecisiz vuruşların hepsinde topun ayaktan çıktığı andaki hızının ortalama $21.73 \pm 1.87 \mathrm{~m} \cdot \mathrm{s}^{-1}$ olduğu, literatürde de top çıkış hızının bu hızlarda olduğu gözlenmiştir. Yüksek top hızı, kalecilere daha kısa reaksiyon zamanı tanıması ve futbolcunun gol yapma şansını artırması açısından önemlidir (Dörge ve diğ., 2002). Çalışmada elde ettiğimiz ortalama hız ile topun gol çizgisini 0.51 saniyede geçeceği hesaplanmıştır. Bu kadar kısa sürede gerçekleşen bir olayda kalecinin vuruş sonrasında hareketlenmesi handikap olarak değerlendirilse bile teknik kapasitesi yüksek oyuncuların yapacağı vuruşlarda erken hareketlenme ile açık bırakılan köşeye yapılan net vuruşların gol olacağı sonucu çıkarılmaktadır. Noël ve diğ. (2015) ve Weigelt ve Memmert (2012)'in yaptığı çalışmalarda bu savımızı desteklemektedir.

Diz ekleminin destek ayağın yere konduğu andan başlayarak top ayaktan çıktıktan sonrasına kadar geçen 30 karelik sürede $76.14 \pm 18.8$ derecelik bir açı taradığı gözlenmiştir. Yapılan çalışmada să̆ ve solda bulunan hedefler birlikte tek bir yön olarak değerlendirildiğinde sağ köşeye yapılan kalecili ve kalecisiz vuruşlarda top temas anında ki ortalama diz eklem açısı (sırasıyla: $148.13 \pm 2.97^{\circ}, 148.19 \pm 0.85^{\circ}$ ) sol köşeye yapılan vuruşlardaki ortalama diz eklem açısından (sırasıyla; $135.70 \pm 2.97^{\circ}, 133.79 \pm 4.51^{\circ}$ ) daha geniş açılarda ve açısal hızlarda (sırasıyla; $1052.731 \pm 445.27^{\circ} . \mathrm{s}^{-1}$, $\left.1038.95 \pm 163.11^{\circ} . \mathrm{s}^{-1}, 1639.2 \pm 1.33^{\circ} . \mathrm{s}^{-1}, 1628.3 \pm 12.97^{\circ} . \mathrm{s}^{-1}\right)$ olduğu gözlenmiştir. Bu farklılığın ayağın topla temas etmesindeki doğru pozisyonu oluşturabilmek ve hedefe vuruş yapabilmek için kalça ve alt bacak dışa rotasyonunun sağ köşeye yapılan vuruşlarda sol köşeye yapılan vuruşlara göre daha fazla olmak zorunluluğu ile açıklanabilir. Scurr ve Hall (2009) gol çizgisi üzerinde belirledikleri 2 hedefe yapılan penaltı vuruşlarında yaklaşma açısının önemi incelemişler, katılımcıların kendi istedikleri yaklaşma açısını kullanarak yaptıkları vuruşlarda 156.2 \pm 10.1 derecelik bir diz açısı ile topa temas ettiklerini belirtmişlerdir. Bu araştırmada bulunan temas anındaki diz eklem açısı değerlerinden yüksek ortalama ve standart sapma değerlerinde olması çalışmada seçtikleri katılımcıların amatör-hobi olarak futbol oynayan oyunculardan seçilmiş olmasıyla açıklanabilir. Aynı şekilde ayak bileği eklem açısı değerlendirildiğinde sağ köşeye yapılan kalecili ve kalecisiz vuruşlarda top temas anında ki ortalama ayak bileği eklem açısı (sırasıyla: $126.16 \pm 1.08^{\circ}$, $130.46 \pm 4.02^{\circ}$ ) sol köşeye yapılan kalecili ve kalecisiz vuruşlardaki ortalama ayak bileği eklem açısından (sırasıyla: $134.69 \pm 0.5^{\circ}, 135.85 \pm 2.03^{\circ}$ ) daha küçük açılarda top ile temas etmiştir. Sağ alt köşeye yapılan vuruşlardaki ayak bileği eklem açısı topla temas anı ve topun çıkış anı parametreleri göz önüne alınarak değerlendirildiğinde sol alt ve sol üst köşeye göre anlamlı farklılıklar belirlenmesi ayağın dorsal fleksiyonu ile açıklanabilir. Yine Scur ve Hall (2009)'ın penaltı vuruşunda belirlenen hedeflere yapılan vuruşlarda yaklaşma açısının önemini inceledikleri çalışmada ayak bileği eklem açısının $130.2 \pm 11^{\circ}$ ile topa temas ettiğini belirtmişlerdir. Bu çalışmadaki kalecili ve kalecisiz vuruşlarda ayak bileğinin topa temas ettiği andaki eklem açılarına benzer olmak ile birlikte standart sapma değerlerinin fazla olduğu gözlenmiştir. 
Ayak bileği açısının literatürle benzerlik göstermesi belirli bir hedefe yapılacak vuruşlarda, kalça ve alt bacak hareketinin kinematiğinin etkisinin yanında ayağın kinematiğinin topun belirlenen hedefe gitmesinde önemli derecede etkili olduğu söylenebilir. Ayağın topa temas yüzeyinin yanı sıra üç boyuttaki hareketi topun hızını etkilediği gibi gidiş yönü ve açısını da etkileyecektir (Kawamoto ve diğ., 2007). Nitekim ayak üyesinin z ekseninden (yatay/yana) bakıldığında kalecili ve kalecisiz yapılan vuruşlarda top temas anı ve top temas sonrası açısal değerlerinde sağ ve sol köşelere yapılan vuruşlarda farklılık gözlenmiştir. Sağ köşeye yapılan vuruşlarda ayağın yatay ile yaptığı açının sol köşeye göre daha geniş açılarda gerçekleştiği bulunmuştur. Bu farklılığın sağ köşede bulunan hedeflere yapılan vuruşlarda kalça ve alt bacak eksternal rotasyonunun fazla gereksinimi, sol köşeye yapılan vuruşlarda kalça ve alt bacak üyelerinin iç rotasyona gereksinimi ile açıklanabilmektedir. Ayak üyesinin x ekseninden (yatay/öne) bakıldığında top temas anı ve top çıkış anındaki açısal değerler arasında büyük farklılıklar gözlenmemiştir. Gözlenen bu değerlerin Kawamoto ve diğ. (2007)'nın belirttikleri ayağın momentumunu topa aktarabilmek için ayak bileğinin katılığını koruması gerektiği ile örtüşmektedir. Bu araştırmada da top temas ve çıkış anındaki ayak bileğinin z ekseninden (yatay/yana) ve x ekseninden (yatay/öne) bakıldığında yatayda ve dikeydeki hareketinin aşırı farklılıklar göstermediği görülmüştür. Bu gözlem de Hong ve ark (2013)'nın yaptığg çalışmayı desteklemektedir. Fakat topa vuruş hareketinin yüksek hızda olmasından dolayı ayak bileği eklemindeki katılığın ne derece bozulup bozulmadığını görmek için daha yüksek hızlarda çekim yapılması gerekmektedir.

\section{SONUÇ}

Sonuç olarak kalede kaleci olmasının penaltı vuruşunun kinematiğini etkilemediği, buna karşın hedefin topa vuruş kinematiği üzerinde önemli bir etkisinin olduğu belirlenmiştir. Hedefler arasındaki farklılıkların katılımcılarımızın dominant bacaklarının sağ bacak olması ve hedef yönü ile vuruşun kinematiğinin vuruş yapan bacağın seçilen hedefe göre dışa ve içe rotasyon gereksinimlerinin farklılaştığı belirlenmiştir. Topun yönünün belirlenmesinde ayağın topla temas ettiği yüzey kadar ayağın kinematiği de önemlidir. Üst bacak üyesinin topla temas süresince yapacağı dış-iç rotasyonlar ile birlikte ayağın topla temas ettiği bölge ve topa temas süresince üç boyuttaki segment hareketi topun gideceği yönü, hızı ve spini belirleyecektir. Futbolda gol atmak için kalecinin uzanamayacağı alanlara vuruş yapma zorunluluğu topa vuruş yapan bacağın kinematiğini önemli hale getirmektedir. Dolayısıyla vuruş esnasındaki alt ekstremite doğrusal ve açısal kinematiği önem kazanmaktadır. Ayak bileği ve diz ekleminin açısal değerleri ve hızları değerlendirildiğinde hedefe göre farklılık gösterdiği, farklılığında vuruş yapan bacağın topla salınımı ile ilişkili olduğu belirlenmiştir. Dizin açısal hızındaki farklılıklar ayağın topa teması için doğru pozisyonu oluşturarak, hedefe isabetli vuruş için kalça ve alt bacak diş rotasyonunun sağ köşeye yapılan vuruşlarda sol köşeye yapılan vuruşlara göre daha fazla olma zorunluluğu ile açıklanabilir. Yine sağ alt köşeye yapılan vuruşlardaki ayak bileği eklem açısının topa temas anı ve topun çıkış anında sol alt ve sol üst köşeye yapılan vuruşlara göre anlamlı farklılıklar göstermesi ayak bileği ekleminin dorsal fleksiyonu ile açıklanabilir. Antrenörlerin penaltı atışlarında tekniği daha iyi olan oyuncuları tercih etmelerinin sebebi dış faktörlerden etkilenmemenin yanında doğru teknik ile topa vurma becerilerinin gelişmiş olmasıdır. 


\section{KAYNAKLAR}

1. $\quad$ Arıtan S, Çilli M, Amca AM. (2010). HUBAG: Üç boyutlu hareket analizi yazılımı. Hacettepe Journal Of Sport Sciences, 21(1), 30-36.

2. Abdel-Aziz YL, Karara HM. (1971). Proceedings of the American Society of Phorogrammety Symposium on Close Range Photogrommetry. Direct linear transformation into object space coordinates in close-range photogrametry. Urbana: Illinois.

3. Bauer G. (1993). Soccer Tecniques, Tactics and Teamwork. (Translated by Elisabeth E. Reinersmann). New York: Sterling Publishing Company.

4. Bing CY, Parasuraman S, Khan MKA. (2012). Electromyography (EMG) and human locomotion. Procedia Engineering, 41 , $486-492$.

5. Dörge HC, Andersen TB, Sorensen H, Simonsen EB. (2002). Biomechanical differences in soccer kicking with the preferred and the nonpreferred leg. Journal of Sports Science, 20(4), 293-299.

6. Diaz GJ, Fajen BR, Phillips F. (2012). Anticipation from biological motion: the goalkeeper problem. Journal of Experimental Pyschology: Human Perception and Performance, 38, 848-864.

7. Dicks M, Davids K, Button C. (2010). Individual differences in the visual control of intercepting a penalty kick in association football. Human Movement Sciences, 29, 401-411.

8. FIFA. Wold cup all time statistic 1930-2014. (22 Mayis 2016). records/worldcup/index.html

9. Hong S, Go Y, Sakamoto K, Nakayama M, Asai T. (2013). Charactaristics of ball impact on curve shot in soccer. Procedia Engineering, 60, 249-254.

10. Isokawa M, Lees A. (1988). A biomechanical analysis of the instep kick motion in soccer. In: Science and Football. Eds. Relly T, Lees A, Davids K, Murphy WJ. London, E\&FN Spon, p. 449-455.

11. Katis A, Giannadakis E, Kannas T, Amiridis I, Kellis E, Lees A. (2013). Mechanisms that influence accuracy of the soccer kick. Journal of Electromyography and Kinesiology, 23(1), 125-131.

12. Kawamoto R, Miyagi O, Ohashi J, Fukashiro S. (2007). Kinetic comparison of side-foot soccer kick between experienced and inexperienced players. Sports Biomechics, 6(2), 187-198.

13. Kellis E, Katis A. (2007). Biomechanic characteristics and determinants of instep soccer kick. Journal of Sports Science and Medicine, 6(2), 154-165.

14. Lees A, Nolan L, (2001). The biomechanics of soccer: A review. Journal of Sports Science, 16, 211-234.

15. Murgia M, Sors F, Muroni AF, Santoro I, Prpic V, Galmonte A, Agostini T. (2014). Using perceptual home training to improve anticipation skills of soccer goalkeepers. Psychology of Sports and Exercise, 15, 642-648.

16. Noël B, van der Kamp J, Memmert D. (2015). Implicit goalkeeper influences on goal side selection in representative penalty kicking task. Plos, 10(8), 1-8.

17. Navarro M, Miyamoto N, van der Kamp J, Morva E, Savalsberg GJP, Ranvaud R. (2013a). Differential effects of task specific practice on performance in a simulated penalty kick under high-pressure. Psychology of Sports and Exercise,14, 612-621.

18. Novarro M, van der Kamp, Ranvaud R, Savalsberg GJP, (2013b). The mere presence of a goalkeeper affects the accuracy of penalty kick. Journal of Sports Science, 31, 921-929.

19. Navarro M, van der Kamp, Ranvaud R, Savalsberg GJP. (2013b). The mere presence of a goalkeeper affects the accuracy of penalty kick. Journal of Sports Sciences, 31(9), 921-929.

20. Nunome H, Asai T, Ikegami Y, Sakurai S. (2002). Three-dimensional kinetic analysis of side-foot and instep soccer kicks. Medicine and Science in Sports and Exercise, 34, 2028-2036.

21. Robertson GDE, Caldwell GE, Hamill J, Kamen G, Whittlesey SN. (2004). Research Methods in Biomechanics. USA, Human Kinetics.

22. Sakamoto K, Geisler G, Nakayama M, Asai T. (2010). Kinematics of the foot joint in female soccer players during the ball impact phase of kicking. Procedia Engineering, 2, 2459-2554.

23. Sakamoto K, Hong S, Tabei Y, Asai T. (2012). Comparative study of female and male soccer players in kicking motion. Procedia Engineering, 34, 206-211.

24. Scurr J, Hall B. (2009). The effects of approach angle on penalty kicking accuracy and kick kinematics with recreational soccer players. Journal of Sports Science and Medicine, 8(2), 230-234.

25. TFF. TFF 1. Lig istatistikleri. (25 Mayıs 2016a). http://www.tff.org/default.aspx?pageID=563.

26. TFF. TFF 2. Lig istatistikleri. (25 Mayis 2016b). http://www.tff.org/default.aspx?pageID=371.

27. TFF. TFF 3. Lig istatistikleri. (25 May1s 2016c). http://www.tff.org/default.aspx?pageID=376.

28. Timmis MA, Turner K, van Paridon KN. (2014). Visual search strategies of soccer players executing a power vs. placement penalty kick. Plos One, 9, 1-16.

29. UEFA. Champions league statictic 1994-2016. (29 Mayıs 2016a). http://www.uefa.com/uefachampionsleague/history/index.html\#. 
30. UEFA. Euro cup statictic 1960-2012. (22 Mayıs 2016b). http://www.uefa.com/uefaeuro/history/index.html.

31. Weigelt M, Memmert D. (2012). Goal-side selection in soccer penalty kicking when viewing natural scenes. Frontier of Psychology, 3, 1-7.

32. Wood G, Wilson MR. (2012). Quiet-eye training, perceived control and performing under pressure. Psychology of Sport and Exercise, 13, 721728.

33. Van der Kamp J. (2006). A field simulation study of the effectiveness of penalty kick strategies in soccer: late alterations of kick direction increase errors and reduce accuracy. Journal of Sports Sciences, 24, 467-477.

34. Zago M, Mott AF, Mapelli A, Annoni I, Galvani C, Sforza C. (2014). Effect of leg dominance on the center of mass kinematics during an inside of the foot kick in amateur soccer players. Journal of Human Kinetics, 10(42), 51-61. 